\section{Outstanding Business Reference Sources 2017}

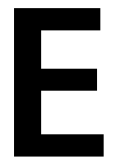
ach year, the Business Reference Sources Committee of BRASS selects the outstanding business reference sources published since May of the previous year. This year, the committee reviewed nine entries; of these, two were designated as "Outstanding," six as "Notable," and one as a "Notable New Edition." To qualify for these designations, each title must meet the conventional definition of reference: a work compiled specifically to supply information on a certain subject or group of subjects in a form that will facilitate its ease of use. The works are examined for the following: authority and reputation of the publisher, author, or editor; accuracy; appropriate bibliography; organization; comprehensiveness; value of the content; currency; unique addition; ease of use for the intended purpose; quality and accuracy of index; and quality and usefulness of graphics and illustrations. Each year, more electronic reference titles are being published. Criteria for evaluating electronic reference titles include the following: accuracy of links, search features, stability of content, and graphic design. Selected works must also be suitable for medium and large academic and public libraries.

\section{OUTSTANDING}

\section{BRASS Business Reference Sources Committee}

BRASS Business Reference Sources Committee contributing members: Benjamin Hall, selections editor; Jordan Nielsen, chair; Lauren Reiter, nominations coordinator; Adele Barsh, Holly Inglis; Felipe Castillo; Erin Wachowicz; and Greg Fleming.

For information contact Benjamin Hall, Business Librarian, University of Colorado, Boulder, CO 803090419; email: benjamin.w.hall@colorado.edu.
Finance for Normal People. By Meir Statman. New York: Oxford University Press, 2017. 488 p. \$34.95 hardcover (ISBN: 978-0-190-62647-1). Contact the publisher for e-book price.

Finance for Normal People provides an outstanding overview of the evolving field of behavioral finance, including insightful and compelling perspectives on behavioral finance theories, evidence, and practice. The book consists of an introduction, twelve chapters, notes, references, and subject and author indexes. It's a valuable resource for patrons interested in exploring the behaviors of investors and markets.

One great strength of this work can be summed up in the reputation and expertise of its author, a professor of finance at Santa Clara University who is known as a pioneer in the field of behavioral finance. In addition to authoring numerous books on the behavioral aspects of investing, Meir Statman has also published in premier scholarly journals such as the Journal of Finance and the Journal of Financial Economics. In his introduction to Finance for Normal People, Statman advocates for a "second-generation behavioral finance" perspective. He suggests that ordinary investors make both smart and foolish decisions as they seek utilitarian, expressive, and emotional benefits from their financial products and services. Statman also acknowledges that these decisions 
and effects are normal and are reflected in financial markets. In Finance for Normal People, Meir Statman relies on expertise to provide a foundational understanding of complex financial principles, and to relay related information on the financial behaviors of individuals and markets.

The organization of Finance for Normal People into wellfocused chapters allows for easy navigation to a specific theme. The book's twelve chapters are arranged in two parts. Part 1, "Behavioral People are Normal People," begins with a summary of the concept of "normal people." Subsequent chapters in this section discuss the wants that drive financial behaviors, cognitive and emotional shortcuts and errors, relevant theories, and existing questions on investor and consumer behavior. Part 2, "Behavioral Finance in Portfolios, Life Cycles, Asset Prices, and Market Efficiency," focuses on the behavior of financial markets and includes chapters on portfolios, saving and spending, asset pricing, and efficient markets. In the final chapter, Meir Statman summarizes practical takeaways from the literature on behavioral finance. The book's subject index also serves as a helpful tool for locating specific topics of interest.

Finance for Normal People would be most suitable for an investor or a patron who is already comfortable with financial terminology and concepts. Written in a clear and understandable style, Statman's book offers a deep dive into behavioral finance topics that are most useful for those seeking to expand their understanding of financial behaviors. Any public or academic library with patrons researching investments or financial markets should add Finance for Normal People to their collection-Lauren Reiter, Penn State University, University Park, Pennsylvania

The International Business Archives Handbook: Understanding and Managing the Historical Records of Business. Edited by Alison Turton. New York: Routledge, 2017. 462 p. \$225 hardcover (ISBN: 978-0-754-64663-1).

Every day, businesses generate substantial volumes of corporate records. Archivists have long served the role of identifying and preserving these documents for the future. As their responsibilities have changed over time, with new demands and changes in technology, there is a need for guidance on processing and managing business archives. The International Business Archives Handbook: Understanding and Managing the Historical Records of Business, edited by Alison Turton, covers important archival concepts and provides practical solutions for managing these historical records.

Turton's handbook is divided into four parts. Part 1 provides an overview of business archives, including a discussion of their history, as well as examples of the ways in which corporate archives provide return on investment (ROI) for individual companies and researchers. The position of the handbook is that archives benefit organizations by serving as a source of institutional knowledge. Many business archives even provide resources for complying with corporate regulations, and documenting corporate social responsibility activities, employee recruitment strategies, and company engagement and retention efforts.

Part 2 describes the different types of business records that archivists' process. There are a core set of records that are common across organizations, including accounting records, memoranda, financial statements, and annual reports. Then there are the industry-specific records. For example, the textile industry has long produced pattern books to facilitate sales and to manage design records. Similarly, architectural firms produce drawings comprised of structural plans, elevations, and sections.

Part 3 is all about the management of business archives. This section provides advice and best practices on the organization, acquisition, appraisal, arrangement and description, preservation, access, and risk management of both physical and digital business archives. Included in this section are many quick-reference tables with samples of policies, forms, plans, and examples of collection documentation.

Lastly, since corporate archivists must continuously demonstrate their value to stockholders; Part 4 of the Handbook focuses on crafting comprehensive advocacy and outreach programs for business archives.

Interspersed throughout the book are case studies covering collections from around the world. Cases range from practitioners developing special archival collections to archivists mitigating mold outbreaks within a collection. At the end of each chapter, a list of notes, references, and further readings are provided. Of the fourteen contributors to the Handbook, most are academics and corporate archivists with diverse backgrounds and experiences. Since many of these authors are also based in the United Kingdom, material can be easily adapted and readily applied in other European business archives.

This outstanding title is an invaluable guide for a range of professionals in both special and academic libraries. Archivists will find this Handbook particularly useful for advising on gift agreements, locating disaster prevention and mitigation plans, and providing classification schemas for business archives. Business historians and other researchers will also find this Handbook useful for understanding the types of archival records available, where they're located, and how they've been arranged or described. Finally, The International Business Archives Handbook will provide business librarians with new insights into the world of business archives, which will ultimately assist them in working with students and faculty.-Felipe Castillo, Seattle University

\section{NOTABLE}

Research Handbook on Gender and Innovation. Edited by Gry Agnete Alsos, Ulla Hytti, and Elisabet Ljunggren. Cheltanham, UK; Northampton, MA: Edward Elgar, 2016. 304 p. \$175 hardcover (ISBN: 978-1783478118).

In today's business environment, the terms innovation and entrepreneurship are basically synonymous. Although 


\section{FROM COMMITTEES OF RUSA}

innovation is often defined very broadly, innovation and entrepreneurship are inextricably linked and are often discussed within the context of economic development. What is seldom discussed, however, is the relationship between gender and innovation. Since the research on innovation so often highlights male innovators and male norms, women's innovation and epistemologies have been fundamentally ignored. In the Research Handbook on Gender and Innovation, a group of thirty-three researchers examine gender norms across multiple contexts to illuminate the effect gender has on innovation policy and organizational management.

By acknowledging the scarce, but evolving, literature on gender and innovation, the Handbook highlights some of the entrenched gender stereotypes that contribute to the relative invisibility of women innovators. The book is divided into five parts. Part 1 tackles the literature analysis-suggesting research agendas for studying innovation teams and social constructs. Part 2 of the book shows how innovation is understood in different parts of the world, specifically in East Africa, Latin America, and Europe. In part 3, innovation processes are discussed within different organizational settings, ranging from public sector health care to mining and forestry. In the final two parts (4-5) of the Handbook, the authors examine the role that gender plays in innovation policy and material production.

The Research Handbook on Gender and Innovation provides a foundation for understanding gender disparities in innovation policies, studies, and organizational practices. This Handbook would be useful for researchers examining gender within new, small, or disruptive business environments. This notable title would also be invaluable for anyone studying entrepreneurial behavior in the context of diversity.-Benjamin Hall, University of Colorado, Boulder

The Big Book of Dashboards: Visualizing Your Data Using RealWorld Business Scenarios. By Steve Wexler, Jeffrey Shaffer, and Andy Cotgreave. Hoboken, NJ: Wiley, 2017. 432 p. \$49.95 paperback (ISBN: 978-1-119-28271-6). \$32.99 e-book (ISBN: 978-1-119-28308-9).

As businesses and researchers rely more and more on quantitative data, demand grows for research methods that depict data in meaningful ways. Today, one of the leading practices for presenting business intelligence data are through data visualizations. Visualizations are an emerging research topic in academia, as well as burgeoning career fields like data science, economics, and business strategy. Data dashboards are used to "monitor conditions and/or facilitate understanding" (xiv), and they've become very useful tools for researchers working in data rich environments. Wexler, Shaffer, and Cotgreaves's The Big Book of Dashboards offers a one-stop resource for identifying data dashboard design principles, use cases, and best practices. This book is a convenient reference for anyone doing statistical reporting or analysis.

The early chapters of The Big Book of Dashboards provide a foundational overview of data visualization concepts. The proceeding twenty-eight scenario chapters offer use cases, which pose specific business process problems accompanied by the dashboard that helps solve the problem. Scenarios are drawn from many fields, including education, customer service, healthcare, marketing, sports administration, transportation, human resources, hospitality, energy, information technology, finance, and economics. Dashboard formats referenced in the book include print reports as well as interactive and online displays. Dashboard functions include time monitors (e.g., goal progress, resource utilization), rankings, sentiment analysis, performance comparisons, and simultaneous displays of multiple variables.

Part 3, "Succeeding in the Real World," includes seven chapters that offer best practices for designing dashboards. The book also contains a glossary of chart types, a bibliography and an index.

The Big Book of Dashboards: Visualizing Your Data Using Real-World Business Scenarios draws from the experiences of three data visualization consultants: Steve Wexler, Jeffrey A. Shaffer, and Andy Cotgreave. Although the authors maintain considerable expertise in Tableau, a popular, leading visualization software tool; they wrote The Big Book of Dashboards for anyone developing business dashboards on any platform. They wanted this book to be platform-agnostic and for the foundations and the real-world examples within to be adaptable in everyday business cases. By organizing the book based on scenarios, and sourcing additional commentary from other contributors within the data visualization community, the authors provide useful solutions to real world queries.

Because this book is written in clear language and is accompanied by clear, visual examples; the text might be useful for a range of users in both public and academic libraries. The bibliography could also be useful for librarians building a collection in visualization theory.-Adele Barsh, University of California, San Diego

The Data Industry: The Business and Economics of Information and Big Data. By Chunlei Tang. Hoboken, New Jersey: Wiley, 2016. 216 p. $\$ 79.95$ hardcover (ISBN: 978-1-119-13840-2).

The Data Industry: The Business and Economics of Information and Big Data by Chunlei Tang, is notable for its efforts to explain big data using business and economic frameworks. The table of contents includes chapter sections that make it easy for readers to find specific content and the reference lists and the index are both current and comprehensive.

In chapter one, Tang introduces this concept of "the data industry," which she builds on throughout the book by presenting a variety of data-related themes through an economic lens. In chapter two, Tang discusses the different applications of data, effectively classifying data resources into seven types under various distinct domains, including scientific data, administrative data, internet data, financial data, health data, transportation data, and transaction data. In chapter three, Tang provides an overview of the data industry chain's supply and demand relationships to provide a clearer definition of what the data industry is. 
From chapters' four to eleven, Tang provides commentary on existing data innovations, data services, operating models and industrial developments. Tang also relies on several widely known, key players in the data industry to help her illustrate some key and emerging concepts in big data. For example, IBM, Facebook, and Alibaba are each discussed to exemplify operating models that are commonly used in the data industry. In the final chapter, Tang provides an overview of the emerging field of data law and offers suggestions for navigating the legal landscape.

According to the publisher's website and the back cover, this book "bridges the gap between economics and data science to help data scientists understand the economics of big data, and enable economists to analyze the data industry." The structure of the book and the organization of the chapters demonstrate that Tang thoughtfully approached each chapter in a manner that supports this claim. This text would be useful for any advanced students, data professionals, or business librarians investigating the emerging data industry.-Erin Wachowicz, Yale University, New Haven, Connecticut

Handbook on the Economics of the Internet. Edited by Johannes M. Bauer, and Michael Latzer. Cheltanham, UK; Northampton, MA: Edward Elgar, 2016. 608 p. \$330 hardcover (ISBN: 978-0-85793-984-5).

The Handbook on the Economics of the Internet is a notable business reference source that examines that effect of the internet on individuals, organizations, industries, and society. The Handbook is organized into five parts, and includes a table of contents and an index.

Part 1, "Prologue," provides an overview of the economics of the internet, including the world's adoption of the internet. Part 2, "Theoretical Foundations," includes seven chapters that span topics such as cultural economics, productivity, and organization-all within the context of the internet. Part 3, "Institutional Arrangements and Architecture," includes eight chapters covering topics such as the economics of cybersecurity, internet standards, privacy, and copyright. Part 4, "Economics and Management of Applications and Services," includes nine chapters that focus on topics such as the economics of internet searching, big data, virtual worlds, and online advertising. Part 5, "Past and Future Trajectories," concludes the Handbook with two chapters: one that focuses on the evolution of the internet from a socioeconomic standpoint and another that examines how the internet has developed from scientific origins, through commercial times, to the current focus on internet entertainment.

Contributors to the Handbook include researchers from Oxford University, Stanford University, Princeton University, Columbia University, the World Intellectual Property Organization, Google, etc. Due to the variety of business topics covered in this resource, the Handbook on the Economics of the Internet would make an excellent addition to any business reference collection. While this Handbook does cover many business topics, its interdisciplinary appeal should also be noted. For example, although the Handbook contains many chapters that discuss the economic impact of the internet on society and culture, there are many other chapters (e.g., "Online News," and "The evolution of the Internet ... ") that would appeal to researchers from a variety of disciplines.

In summary, the internet has transformed everything from the way humans communicate to the way business is conducted, and the Handbook on the Economics of the Internet offers a thorough examination of the internet's consequences for the curious researcher.-Jordan Nielsen, Rutgers University, Piscataway, New Jersey

The Routledge Companion to Business History. Edited by John F. Wilson, Steven Toms, Abe de Jong, and Emily Buchnea. Abingdon, UK; New York: Routledge, 2017. 394 p. \$240 hardcover (ISBN: 9780415855563). \$67.95 e-book (ISBN: 9780203736036).

The editors of The Routledge Companion to Business History state in the introduction that their intent is to provide background, methodologies, and an international scope for a wide range of scholars, particularly in the social sciences. For public and special libraries, the topics covered could be of interest to managers, entrepreneurs, and even administrators.

The book is divided into five parts, with twenty-four chapters in total. Each part provides a title theme: "The Discipline of Business History," "Business Ownership," "International Varieties of Capitalism," "Institutions," and "Management and Ethics." Introductory sections within each part offer valuable overviews for business professionals and for students looking for background information on the global reach of business. The Companion also provides an overview of the methodologies traditionally used in business history research. It includes some of the known challenges concerning research methods, and suggests that the growth of business history as a field of study is becoming more interconnected with social science research.

The Routledge Companion to Business History offers broad coverage on topics in business history, including many topics marked by contemporary interest. Examples of chapters that might be of interest for business professionals, include chapters on personal and managerial capitalism, financial capitalism and stock markets, charities and social enterprises, and banks and private finance. The Companion also provides perspectives on business ethics, fraud and financial scandals.

For those interested in global coverage, the United Kingdom and Western Europe are well represented here. Part 3, "International Varieties of Capitalism," includes chapters on African business history, Latin American history, settler capitalism in Australia and enterprise in Soviet Russia. The introduction states that Asia was excluded in this section because it could not be covered as a single entity.

The Routledge Companion to Business History is an excellent addition to any academic business library. The methodology overview and the book's international scope provide valuable insight for researchers in this subject area.-Holly Inglis, University of Toronto 


\section{FROM COMMITTEES OF RUSA}

The Startup Checklist: 25 Steps to a Scalable, High-Growth Business. By David S. Rose. Hoboken, NJ: Wiley, 2016. 320 p. \$32 (ISBN: 978-1-119-16379-4).

The process of designing, launching, and managing a new business is usually overwhelming. As an entrepreneur just starting out, mistakes are inevitable. For enthusiastic startups and youthful entrepreneurs, this process of turning an idea into a business gets very complicated, very early on in development. In the case of the startup, applying best practice means learning from the experience of others. David S. Rose's The Startup Checklist: 25 Steps to a Scalable, HighGrowth Business, provides a roadmap to avoiding mistakes when starting a high-growth business venture. Backed by more than forty-five years of experience in business and venture capital, David S. Rose provides the insight and the tools needed to start smart and succeed big.

As a companion resource to some of the standard startup classics, The Startup Checklist is notable for its contents. The book contains twenty-five "Key Action Steps" (chapters) divided into three parts. In part 1, "Prepare to Launch," Rose discusses the importance of developing a workable business model, including expert insight on how to craft a lean business plan, how to evaluate competition, recruit talent, build brand recognition, network effectively, and allocate equity. In part 2, "Launch and Build Your Company," Rose provides specs for incorporating, recruiting, managing data analytics, establishing accounts, incentivizing employees, and choosing key platforms, vendors, and technologies. In the final part, chapters 19-25, Rose advises on raising funds, dealing with investors, calculating valuation, and planning for to exit your business.

As a list, The Startup Checklist is intended to provide discernible guidance for entrepreneurs. In addition to the prose, appendixes contained within include the author's own curated reading list, sample company financial documents, and a link to The Startup Checklist Online. For entrepreneurs or students seeking practical instruction on starting and managing a business, David S. Rose's book is a one-stop checklist to launching and exiting the right way.-Benjamin Hall, University of Colorado, Boulder

\section{NOTABLE NEW EDITION}

Richard K. Miller \& Associates Market Research Handbooks. Loganville, GA: Richard K. Miller \& Associates. \$1,600 for a collection of six.

Richard K. Miller and Associates (RKMA) has been publishing market research and forecasts since 1972. They currently focus on consumer markets and publish twelve titles, covering consumer behavior, consumer marketing, business-to-business marketing, and seven major industry segments. Each title is updated biennially. Titles in the forthcoming 2018 package, include Business-to-Business Marketing; Consumer Marketing; Consumer Use of the Internet and Mobile Web; International Consumer Markets; Sports Marketing; and Restaurant Food and Beverage Market Research Handbook.

RKMA handbooks are designed as starting points for research, offering short narrative overviews of broad industries or marketing segments. Handbook profiles and statistics are synthesized from many different sources, including government agencies, trade publications and market research companies. Each handbook begins with broad information on its topic and then drills down into narrower segments. A typical section provides summary statistics on a specific market segment along with additional reference sources.

One example of a handbook with broad coverage is the section on wine from the Restaurant, Food \& Beverage Market Research Handbook. Reporting on the wine industry segment, this section covers total consumption, wholesale and retail sales, consumer demographics and leading brands. Each handbook also concludes with extensive appendixes that cover important trade journals, trade associations, and major analysts that cover the market.

RKMA online handbooks can be accessed as PDF files directly from Richard K. Miller and Associates. Though the handbooks are not indexed, they can be searched using PDF reader software.

RKMA handbooks are great resources for sizing markets and identifying key segments in their covered industries, and would be a great resource for academic libraries and public libraries that serve entrepreneurs._Greg Fleming, University of Chicago 